\title{
Exploring the Role of Trust in Scientists to Explain Health-Related Behaviors in Response to the COVID-19 Pandemic
}

\author{
Ebru Zeynep Muğaloğlu ${ }^{1}$ (D) - Zeynep Kaymaz² (D) Muhammet Emin Mısır ${ }^{3}$ (D) \\ Canan Laçin-Şimşek ${ }^{3}$ (i)
}

Accepted: 9 January 2022 / Published online: 5 February 2022

(c) The Author(s), under exclusive licence to Springer Nature B.V. 2022

\begin{abstract}
The devastating COVID-19 pandemic has cast a light on the question of why trust in scientists is important. This mixed-method study aimed to explore the study participants' trust in scientists about getting the COVID-19 vaccine. It also aimed to reveal which key sources of information participants followed about the pandemic. Participants' health-related behaviors and justifications for their behaviors as a response to the pandemic were also explored to understand how trust in scientists and sources of information played a role in the fight against COVID-19. The responses of 1233 participants across Turkey were analyzed. The findings indicated that trust in scientists and compliance with the scientists' suggested behaviors among the participants were quite high. It was also revealed that, for both trust and non-trust groups, participants questioned the reliability of information and the sources. Participants justified their behaviors mainly by referring to policies, e.g., masks, distance, and hygiene, developed and implemented with the collaboration of government, scientists, and the World Health Organization. Moreover, trust issues regarding scientists, government authorities, or other citizens were mentioned in participants' justifications. The current study also shed light on the importance of building trust through an open and healthy dialogue among scientists, government authorities, and the public to overcome the COVID-19 pandemic. The study highlighted the need for scientifically informed citizens to
\end{abstract}

Ebru Zeynep Muğaloğlu

akturkeb@boun.edu.tr

Zeynep Kaymaz

zeynep.kaymaz@boun.edu.tr

Muhammet Emin Misir

muhammetemin@sakarya.edu.tr

Canan Laçin-Şimşek

csimsek@sakarya.edu.tr

1 Faculty of Education, Department of Mathematics and Science Education, Boğaziçi University, Istanbul, Turkey

2 The Institute for Graduate Studies in Social Sciences, Boğaziçi University, Istanbul, Turkey

3 Faculty of Education, Department of Mathematics and Science Education, Sakarya University, Sakarya, Turkey 
deal with the problems, i.e., misinformation and disinformation, in the post-truth era such as not jeopardizing effective solutions to eliminate the pandemic, e.g., taking the vaccine.

\section{Introduction}

One of the goals of science education in the $\mathrm{K}-12$ curriculum is to raise scientifically informed citizens (Ateş, 2020; Ford, 2008). Scientifically informed citizens are "able to understand scientific claims as tentative, as deserving a fitting degree of confidence and skepticism - a stance that is neither gullible nor inflexible, but appropriately critical" (Ford, 2008, p. 147). Having such citizens is crucial, especially when citizens need to take action based on informed decisions to be a part of a solution to a science-related issue such as the COVID-19 pandemic. COVID-19 is an infectious disease caused by the coronavirus. As highlighted by Erduran (2020), the COVID-19 pandemic showed that "understanding science in context is not a luxury but a necessity in our times" (p. 38). In addition to understanding scientific explanations in the context of COVID-19, citizens need to be critical of related claims from various sources; they also need to be "aware of the information that would increase confidence in them [claims]" (Ford, 2008, p. 147).

The COVID-19 outbreak has remained a science-related issue and has constituted a public health emergency of international concern. Policymakers and governments worldwide have been forced to develop and implement the necessary policies to fight the pandemic immediately following the outbreak. The problem's solution required close collaboration between policymakers and the scientific community to develop and implement policies in line with suggestions from the scientific community. Therefore, the concept "trust in scientists" has become a hot topic amid the discussions on tackling one of the most crucial public health emergencies in history. To be able to take prompt and proper actions to overcome the pandemic, on the one hand, politicians and government authorities were expected to trust in scientists and make policies in accordance with their explanations and suggestions. On the other hand, citizens were expected to make informed decisions in line with these explanations and suggestions and take action accordingly to mitigate the risks of the spreading virus, hospitalization, and death. Thus, successful policymaking and implementation addressing the problem correctly necessitated "trust in scientists" as a common denominator for both sides, i.e., governments and citizens.

There is a broad literature on the definition of trust as a general concept and in relationship with building an epistemic claim (Baier, 1986; Hardin, 2002). In general, trust requires a three-place relationship between the truster, the trustee, and the object of trust. For the purposes of this article, we expected the public to trust scientists with the object of trust, that is a set of propositions to explain the pandemic and course of actions to be protected from the COVID-19 disease. Trusting someone with a proposition refers to epistemic trust (Irzik $\&$ Kurtulmus, 2021). Irzik and Kurtulmus (2021) discussed the conditions under which the public invests warranted epistemic trust in scientists. These include reliable production of scientific knowledge by scientists, its dissemination through high-quality science journalism, governmental agencies and media, and its proper evaluation by the public.

Scientifically informed citizens look for reliable sources of information to understand scientific claims, disregard unreliable sources of information that involve misinformation or disinformation, and make their decisions based on scientific explanations. Misinformation and disinformation refer to partially and entirely incorrect information (Wardle \& Derakhshan, 2017). On the other hand, misinformation does not necessarily result from a conscious effort 
to mislead, whereas disinformation constitutes the intention to manipulate and harm. Just like in many parts of the world, although there have been widespread warnings from scientists in Turkey about the devastating outcomes of the COVID-19 virus in media, $11 \%$ of Turkish citizens rejected the existence of the virus, and 33\% claim the pandemic is being "exaggerated" (Gölemerz et al., 2020). Therefore, not all citizens trust the scientific explanations but are willing to accept misinformation or disinformation. From a similar point of view, Greene and Murphy (2021) reminded that warnings published by media organizations and governments suggest that people search the reliability of news before sharing it on social media.

In the chaotic environment created by the pandemic, the scientific community has been bombarded with misinformation and disinformation. As an example of misinformation regarding asymptomatic COVID-19 positive cases, in which a person infected with the virus shows no symptoms, it was believed that they were not spreading the virus (Lee et al., 2020). Another example is, contrary to scientists' explanations, the claim about the transmission of the COVID-19 virus through 5G waves frequently appeared in social media and led to protests in some countries (Meese et al., 2020). UNICEF (2021) also stated that some people still believe that 5G technology causes and spreads COVID-19, and they act suspicious about using cell phones. Another fear fueled by social media is based on the misconception that a vaccine will somehow alter human DNA (Goodman \& Carmichael, 2020). The fast and massive spread of misinformation, disinformation, and the denial of well-established scientific explanations are considered serious issues in the post-truth era (McIntyre, 2018; Prado, 2018).

Within this rationale, the current study aimed to explore self-reported pandemic behaviors, sources of information, and justifications of participants in Turkey who trusted in scientists and who did not trust in scientists about getting a vaccine in the context of COVID19 between March 2020 and January 2021. This study's research questions are as follows:

1. How did participants who trusted in scientists and those who did not trust in scientists about getting the COVID-19 vaccine report their source of information and healthrelated behaviors during the three defined periods of the pandemic between March 2020 and January 2021 ?

2. How did participants who trusted in scientists and those who did not trust in scientists about getting the COVID-19 vaccine justify their health-related behaviors?

\section{Literature Review}

\subsection{Health-Related Behaviors in Response to the COVID-19 Pandemic}

The World Health Organization (WHO) (2020a) declared the COVID-19 virus a global pandemic in March 2020. The WHO (2021) gathered scientists and health professionals in order to develop standards and norms to prevent the spread of COVID-19 and to protect people from the disease. Based on the scientific research, the WHO recommended a list of precautions for protection, such as social distancing, wearing a mask, and cleaning hands.

Right after the outbreak, several research projects about COVID-19 were conducted to investigate public understanding of the disease and whether people were following the recommended behaviors. Clements (2020) conducted one of these studies in March 2020, after national recommendations for preventive measures were released in the USA, and explored behaviors associated with COVID-19. According to the study results, the rate of wearing a mask outside home was reported as $23.60 \%$ among the participants $(n=1034)$. It 
was also found that $62.77 \%$ of the participants reported they spent money more than usual to store food, cleaning, and personal hygiene products; $30.95 \%$ of participants reported visiting crowded places. Additionally, individuals with at least a university degree or above tended to wear a mask more than high school graduates. In another study in the USA in July 2020, the rate of wearing a mask among respondents of the survey was found $79 \%$ $(n=840)$ (Romer \& Jamieson, 2020). The researchers also measured washing hands or using a sanitizer, keeping distance from others, avoiding gatherings of more than 10 people, staying at home, etc. In China, where wearing a mask was mandatory, $98.0 \%$ of survey respondents reported that they wore masks in public areas (Zhong et al., 2020). Pagliaro et al. (2021) also conducted a multinational study in April to May 2020 and measured the self-reported behaviors of participants related to the pandemic (i.e., wearing masks). According to the mean levels of declared adherence to those pandemic behaviors, Turkey was ranked third after Chile and Argentina, among 23 countries.

In Turkey, Bostan et al. (2020) implemented a study in late March 2020, when the effect of the disease was severe, aiming to reveal participants' behaviors and social trust, sensitivity to pandemic, and protection against pandemic $(n=1586)$. According to the study results with respect to protection behaviors, hygiene, social distance, and staying at home were found to be the highest means, respectively. In addition, participants stated that the people they lived with also complied with the rules. The findings revealed that, when people were most vulnerable to the pandemic, they were implementing maximum individual efforts for protection. Another study focused on exploring the reasoning behind the behaviors of preservice biology teachers $(n=26)$ in the COVID-19 context was carried out by Han-Tosunoglu and Ozer (2021). Their study revealed most of the participants based their decisions about health-related behaviors on rational and moral reasoning. In another study, trust in science, scientists, and government was found to be crucial in directing people's behavior such as social distancing and taking precautions against infected people among nine countries (Bicchieri et al., 2021).

Briefly, the literature above indicated that people mostly followed the recommended behaviors suggested such as masks, isolation, and hygiene to fight the COVID-19 pandemic. However, despite all scientists' warnings, some people have believed the fake news and acted against these suggestions. For instance, they rejected vaccination (Oksay, 2021) which have led to unfortunate outcomes (Coleman, 2020). Thus, it is also important to understand the participants' reasoning, the role of trust in scientists, and the source of information in people's actions in response to the COVID-19 pandemic.

\subsection{Source of Information in the Context of COVID-19}

WHO Director-General Tedros Adhanom Ghebreyesus said, "We're not just fighting an epidemic; we're fighting an infodemic," (Barzilai \& Chinn, 2020, p. 107). Official websites of scientific institutions and organizations such as the WHO provide evidence-based scientific information based on reliable sources. On the other hand, with the outbreak of the pandemic, there has been a spike in news about the COVID-19 virus; explanations from scientists, politicians, and healthcare providers in media; and speeches of several nonexperts on TVs as well as the rapid spread of information and misinformation in social media. These information and misinformation bombardments made the situation confusing and overwhelming for lay people to follow. Timonen (2020) stated that, as responsible citizens, individuals need to survive within the "news jungle". This infodemic calls attention to the importance of questioning the reliability of the information and its source. People who 
follow multiple resources for information need to possess strong thinking skills, understanding of basic scientific knowledge, scientific method, and the nature of science. Unless an individual is informed via science, appreciates its tentative nature, and considers the strength of scientific evidence, it is not easy for that individual to differentiate reliable scientific explanation from a pseudoscientific explanation, misinformation, or disinformation. In other words, understanding science is an essential tool for critical review of the news (Timonen, 2020) and to determine the veracity of the information.

Lep et al. (2020) conducted a study with 1718 participants in Slovakia at the early stages of the pandemic, revealing that the majority of the participants preferred online news portals $(74.1 \%)$ and TV news $(65.7 \%)$ as COVID-19 information sources. Social media $(61.0 \%)$ and the official webpage of the National Institute of Public Health (NIPH) (55.3\%) were other highly followed information sources, while healthcare professionals were only preferred by $11 \%$ of the participants. Contrary to this, participants found scientists and doctors more credible as sources of information on COVID-19 and expressed high level of trust in them to gain information, while they exhibited lower level of trust for politics, the MoH in Slovakia, and social media (Lep et al., 2020). In line with these findings, a study in the USA also revealed that healthcare professionals were the most trusted sources of information followed by health officials (i.e., National Institutes of Health), while social media was the least-trusted source of information (McFadden et al., 2020).

Social media allows the freedom to share not only scientific information but also personal opinions, among which there could be misleading information. For instance, several studies revealed that vaccine hesitancy is associated with misinformation in social media (Allington et al., 2021a; Jennings et al., 2021). Therefore, it can be argued that, when people search for information on social media, they may reach both supportive and contradictory information on vaccines, which necessitates being critical as they make a decision to get the vaccine. As an example of a source of information, Myspace, which is a popular social media in the USA, was tracked to explore the public's profile on immunization and vaccines (Keelan et al., 2010). The results revealed that, among $303 \mathrm{blogs}, 52 \%$ involved positive messages in favor of vaccines, while $48 \%$ of the blogs disseminated negative arguments (Keelan et al., 2010). Likewise, 153 YouTube videos in the English language were identified on immunization and classified through content analysis that showed $48 \%$ of the videos conveyed positive, $32 \%$ negative, and $20 \%$ ambiguous messages on vaccines (Keelan et al., 2007). Moreover, $45 \%$ of the negative videos made claims that conflicted with scientific explanations, while none of the supportive videos on vaccines involved contradictions with scientific statements (Keelan et al., 2007).

\subsection{Trust in Scientists}

Trust is a critical construct that guides research within various fields, e.g., psychology, sociology, political science, computer science, the economy. Researchers seek to reach a shared understanding of trust considering various definitions (Bhattacharya et al., 1998; Myers et al., 2017). Rousseau et al. (1998, p. 395) suggested a definition of trust based on the shared aspects of the construct after careful analysis of articles: "Trust is a psychological state comprising the intention to accept vulnerability based upon positive expectations of the intentions or behavior of another". Castelfranchi and Falcone's cognitive theory (Castelfranchi \& Falcone, 1998) identifies four elements of trust: a truster, a trustee, an action, a goal. During this action, the truster accepts the risks and vulnerabilities that the trustee will use the necessary expertise for the benefit of the truster (Myers 
et al., 2017). This reveals two important conditions necessary for trust to occur: risk and interdependence (Rousseau et al., 1998). People do not need to trust when there is no risk because actions can be taken effortlessly in certain conditions. However, the presence of uncertainty requires that one perceives the probability of the loss (Bhattacharya et al., 1998; Rousseau et al., 1998); therefore, trust emerges. Interdependence, as the second condition of trust, necessitates one to rely on others (Rousseau et al., 1998) to reach common goals. For instance, a citizen who decides to get vaccinated based on the suggestions of scientists includes a truster (citizen), a trustee (scientist), an action (getting vaccine), and a goal (to be protected from an illness). Moreover, the case also consists of risk elements such as side effects of vaccines and interdependence such as relying on scientists' work against the risks and uncertainties. On the other hand, the number of people who are opposed to vaccination increased in spite of scientific evidence about its benefits to overcome contagious diseases for more than 20 years (Hamilton et al., 2015), and they reject having any vaccines. This problem perpetuates for COVID-19 vaccination as well, as even people who work in the medical field demonstrate hesitancies in regard to inoculation (Dror et al., 2020).

Trust in science and scientists has been studied as an important variable in research regarding science-driven controversial issues such as evolution (Nadelson \& Hardy, 2015), genetically modified foods (Funk et al., 2015), renewable energy sources (Castell et al., 2015), vaccines (Allington et al., 2021b; Dror et al., 2020; Hamilton et al., 2015), and climate change (Hamilton et al., 2015; Myers et al., 2017; Sleeth-Keppler et al., 2017). Moreover, Myers et al. (2017) highlighted that trust in general scientific research differs when a specific area of science such as climate change and vaccines was defined. A study was conducted in two different states in the USA to investigate whether people trust scientists as an information source on climate change and vaccines and to explore the predictors of trust in environmental scientists (Hamilton et al., 2015). The study measures the trust construct using three versions of one key question for each of the scientific issues, namely, vaccines, climate change, and forest management. For instance, regarding the vaccine issue, participants were asked: "Would you say that you trust, don't trust, or are unsure about scientists as a source of information about vaccines?" (Hamilton et al., 2015, p. 4). According to the results, trust in scientists about vaccines was 70\% in New Hampshire and 57\% in Oregon, both of which were higher than the trust in scientists about climate change in both states. Likewise, Agley (2020) employed a survey study in the USA $(n=242)$ to examine whether there has been a change in respondents' trust in sciences/scientists between the first outbreak of coronavirus in December 2019 and after several months (i.e., March 2020). Out of five points, the mean of the respondents' level of trust in science and scientists was found at 3.82 in December 2019 and 3.81 in March 2020, thus indicating no change.

Since trust in scientists plays a key role for the public to act in line with the suggestions of the scientific community, it is a signal to politicians and government authorities to trust scientists as they make policies and prepare pandemic guidelines in accordance with the suggestions of scientists. This can be supported through the findings of a survey study $(n=718)$ in the USA, which has revealed that the majority of respondents prefer the Centers for Disease Control and Prevention (CDC) or the National Institutes of Health (NIH) (69\%) to lead the pandemic crisis rather than the president or the congress (14\%) (McFadden et al., 2020). In an international study aimed to measure the perceived trust level in a pandemic, ratings of respondents from Turkey $(n=300)$ indicated that the mean level of trust in science was higher than trust in government institutions and fellow citizens (Pagliaro et al., 2021). Based on the findings of the same study, respondents from 18 countries out of 23 expressed a higher level of trust in science than their governments such as in the USA, 
Russia, Germany, Spain, Romania, Australia, and Bangladesh (Pagliaro et al., 2021). In Israeli, trust in science was higher than trust in government (Shinan-Altman \& Levkovich, 2020).

Trust in science, scientists, governments, and fellow citizens (Agley, 2020; Ayalon, 2021; Pagliaro et al., 2021; Plohl \& Musil, 2020), as well as political ideology (Nadelson et al., 2014) and beliefs in conspiracy theories (van Mulukom et al., 2020) may influence how individuals respond to recommended or mandatory behaviors to fight against the coronavirus. Plohl and Musil (2020), in a study with 525 international participants, reported that COVID-19 risk perception and trust in science (two highly and positively correlated variables) are predictors for the public's obedience of suggested preventive behaviors during a pandemic. In other words, behaviors of people who trust in science and perceive COVID-19 as a risk to their health are in line with those suggested pandemic behaviors (Plohl \& Musil, 2020). Concurrently, COVID-19 risk perception and trust in scientists were negatively associated with vaccine hesitancy in a study conducted with a representative sample of UK residents ( $n=4343$ ) (Allington et al., 2021b). To win the fight against the pandemic, trust in science and scientists has become a key factor to make informed decisions for protecting individual and public health (Battiston et al., 2020), complying with COVID-19 protective behaviors (Ayalon, 2021), and getting a COVID-19 vaccine.

Regarding the vaccines, although they were accepted as a safe solution to illnesses by the scientific community (Özceylan et al., 2020; Spencer et al., 2017), COVID-19 vaccines raised several issues such as their side effects and efficiencies (Dror et al., 2020). This may be because the development process of the COVID-19 pandemic vaccine differs from the others, such as use of different techniques, faster development process, and less clinical trials (Lurie et al., 2020). Even though it has been approved by the WHO, a vaccine developed in such unprecedented conditions has led to several issues concerning the results of each brand of COVID-19 vaccine. In such situations, a person needs to weigh the risk of either getting vaccinated under such uncertainty or being infected by COVID-19. Trust can be formed as a result of such uncertain conditions. After all, trust is a psychological condition that leads to making the choice and to act in a certain way, but not the choice or the behavior itself (Rousseau et al., 1998). Within this framework, the present study focused on participants' trust in scientists about getting a vaccine, the sources of information followed by the participants, and the participants' health-related behaviors and their reasons for their actions.

\section{Method}

This study used a convergent mixed-method design (Creswell \& Clark, 2018), which included quantitative and qualitative research methods. This type of mixed method aimed to present, analyze, and bring concepts together and approaches in a complementary way by using various research methods (Creswell, 2014).

\subsection{Participants}

The present study included 1307 participants. Since the conditions of COVID-19 change rapidly, convenient sampling was used to collect data in a very short time. The participants voluntarily answered all of the questions in the survey by clicking the link shared in social media. The study aimed to reveal behaviors of participants from Turkey 
who were over 18 and had no vaccination against COVID-19. Participants under 18 are not legally responsible for their own behaviors. For instance, in order to get a vaccine, permission from their legal guardians is requested. Thus, to some extent, it is the legal guardian's decision to get vaccinated. Also, participants who get vaccinated were also not suitable for the analysis carried out to answer this study's research questions. Therefore, those under $18(n=17)$ who got vaccinated $(n=89)$ before the data collection were excluded from the analysis. Among the remaining 1233 participants included in the data analysis, $68 \%$ and $31 \%$ of them stated their gender as female and male, respectively; further, $1 \%$ of the participants preferred not to state their gender. The age distribution of the participants is shown in Fig. 1. The youngest participant was 18; the oldest one was 77.

Only $2.6 \%$ of the participants were graduates of elementary or middle school; $22.9 \%$ were graduates of high school; $75 \%$ of the participants had an undergraduate $(52.8 \%)$ or graduate degree $(21.6 \%)$. This is to say that the majority of the participants in this study had higher-education degrees.

The participants were from across Turkey, including 72 cities out of 81 (Fig. 2); $41.5 \%$ of participants were from Istanbul (in Marmara Region), which has the highest population (18.49\%) among the cities of Turkey based on the Turkish Statistical Institute (2021). Among the participants, 9.8\% were from Sakarya (in the Marmara Region); $5.7 \%$ were from Ankara (in Central Anatolia).

Briefly, participants were from a variety of age, gender, and education levels. Moreover, participants from seven regions of Turkey had experienced the pandemic with respect to their local conditions. Although convenient sampling was used, the number of participants from each region of Turkey was in parallel with the geographical distribution of the population in that region.

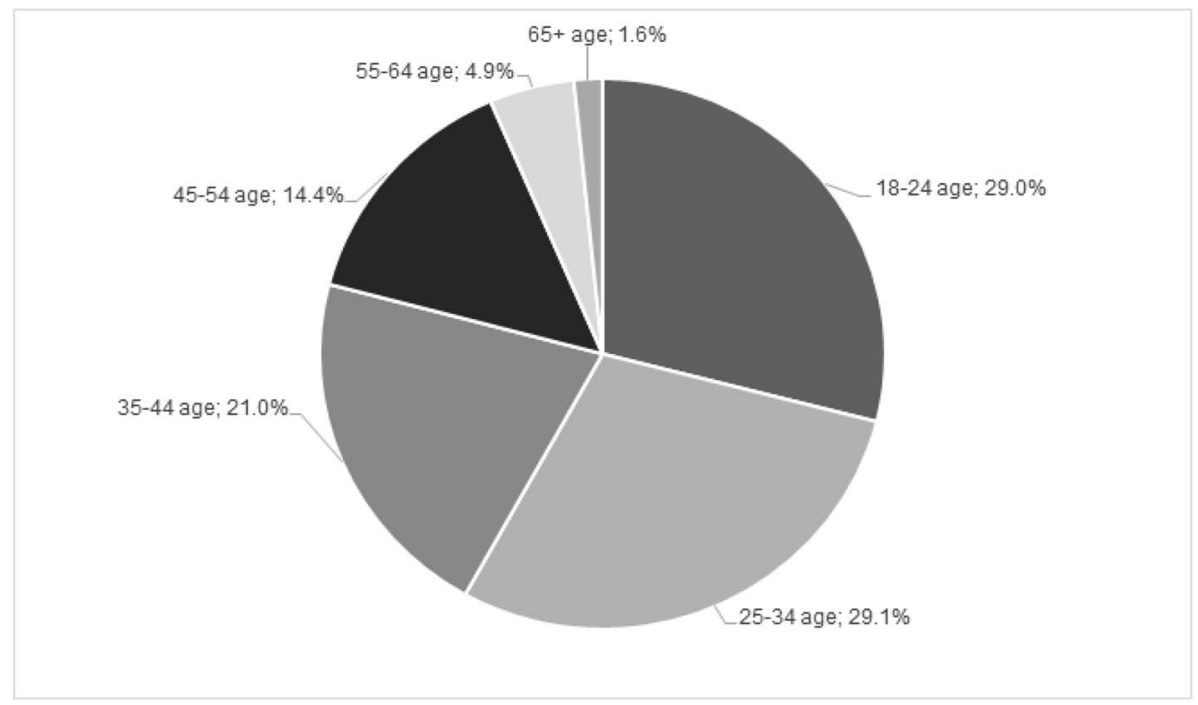

Fig. 1 Percentage distribution of participants' age 


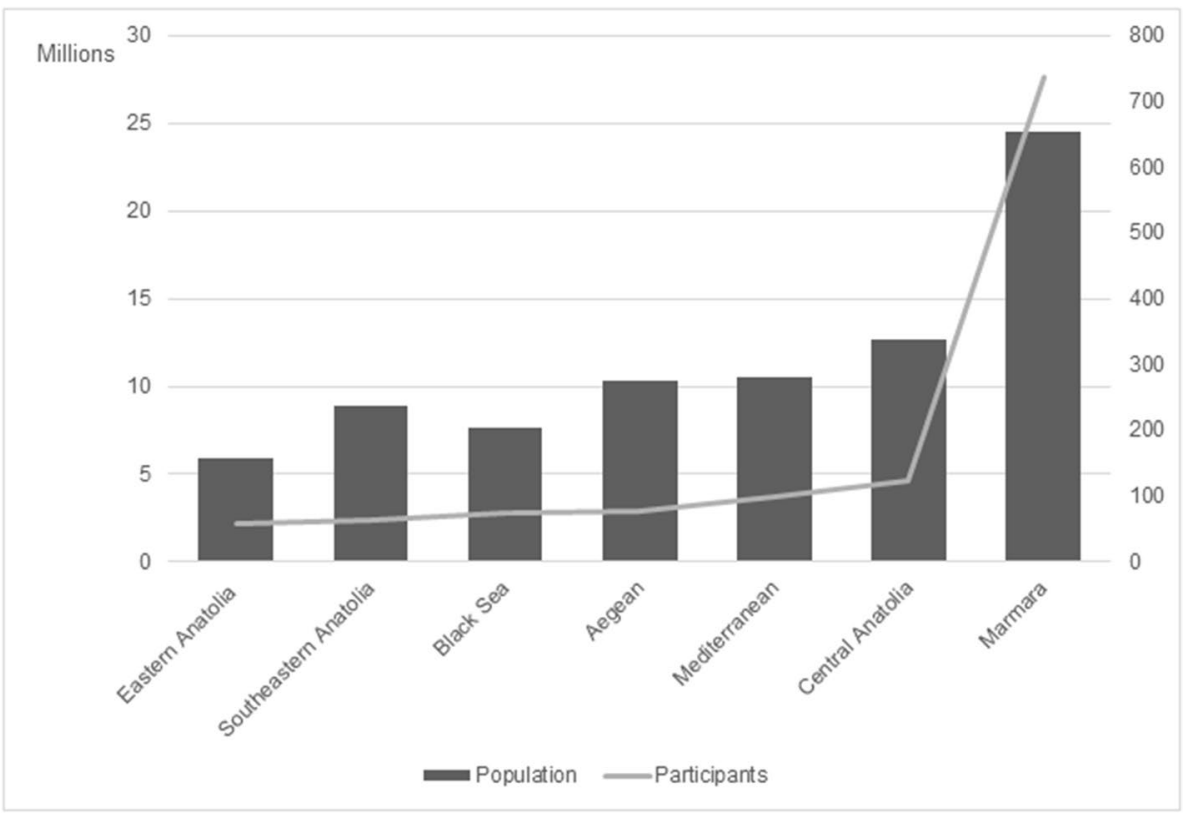

Fig. 2 Distributions of population and participants according to the regions in Turkey

\subsection{Context of the Study: COVID-19 in Turkey}

According to the World Health Organization's (WHO) Coronavirus Timeline Report (, 2020b) and the Turkish Academy of Sciences (2020), a great quantity of patients with unknown causes of pneumonia were reported in Wuhan, China, in late December 2019. Three months later, the WHO (2020a) declared COVID-19 as a pandemic. As Turkish Academy of Sciences (2020) stated that in Turkey, the first COVID-19 case and the first death due to COVID-19 was reported on March 10 and 17, respectively.

During the pandemic, the Turkish Ministry of Health $(\mathrm{MoH})$ shared significant information and data related to COVID-19, such as the number of positive cases, with the public. Moreover, in January 2020, the MoH established the Coronavirus Scientific Board in Turkey. The board listed suggestions for Turkish citizens to protect themselves from the disease. In the light of the discussions with the Scientific Board, the $\mathrm{MoH}$ in Turkey also worked cooperatively with the Ministry of Interior Affairs, and the WHO to develop rules, regulations, and guidelines to overcome the COVID-19 pandemic (Presidency of the Republic of Turkey, 2020).

As in many countries, the number of COVID-19 positive cases in Turkey fluctuated significantly during the year. The rapid increase in COVID-19 cases in Turkey led to taking strong precautions such as staying home; closing schools, restaurants, and shopping centers; and encouraging working from home (Mardin, 2021). On the other hand, when the number of cases decreased significantly, some of these restrictions were removed. For instance, during low COVID-19 positive case periods, restaurants and shopping centers were reopened. The number of COVID-19 positive cases and deaths reported by the MoH in Turkey (2021) is indicated in Fig. 3. Based on the level of precautions, the pandemic period in Turkey was grouped into three periods for the purposes of this study: 


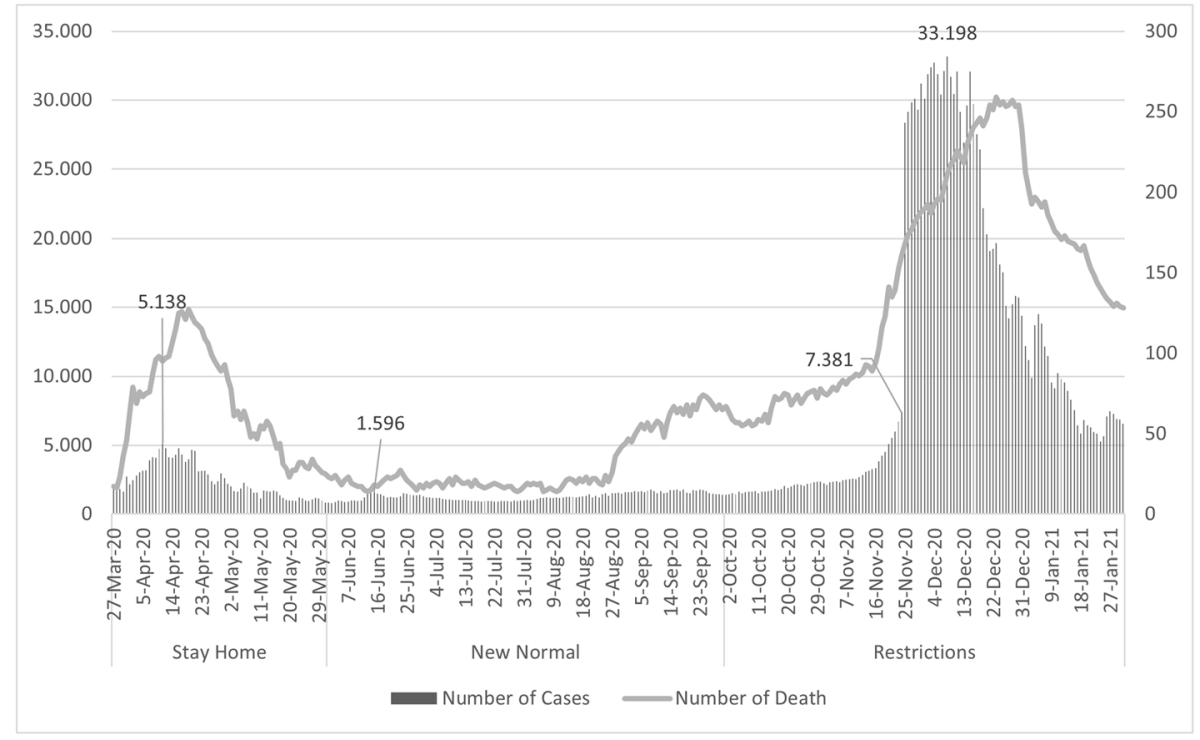

${ }^{\mathrm{a}} \mathrm{MoH}$ in Turkey, 2021

Fig. 3 Number of reported cases and deaths ${ }^{\mathrm{a}}$

- Stay home period (March-May 2020): This period included the time of a partial lockdown after the first positive case was reported on March 11. During this period, a mandatory stay home order was given. During the stay home period, the highest number of cases reported in a day was on April 11, $2020(n=5138)$. Then, the number of cases reported decreased to 839 on May 31, 2020.

- New normal period (June-September 2020): In this period, restrictions were loosened. Stay home order was removed. During this period of the pandemic, the lowest number of positive cases reported in a day was on June 2, $2020(n=786)$, whereas the highest number of cases reported in a day was on June 15, $2020(n=1596)$.

- Restrictions period (October 2020-January 2021): During this period, the level of measures and restrictions was increased. At the beginning of this period, schools were partially opened for in-person education in classes, but, right after a sharp increase in the number of positive cases, they were partly closed. Some restrictions were put in place while the lockdown was lifted. In this period, MoH in Turkey excluded asymptomatic COVID-19 positive cases and announced only the number of seriously ill patients as the number of COVID-19 positive cases until November 25, 2020a. From this date on, $\mathrm{MoH}$ started reporting all COVID-19 positive cases, including the ones showing symptoms and without any symptoms. Hence, the number of COVID-19 cases sharply jumped to 33,198 on November 25 (Pitel, 2020).

\subsection{Data Collection Tool: Survey About Behaviors in the COVID-19 Pandemic}

To examine participants' trust in scientists, health-related behavior, and its justifications during the three defined periods of the pandemic, researchers created the Survey About Behaviors in the COVID-19 Pandemic. The survey started with a consent form that 
consisted of the research purpose, clarification about the right to withdraw at any point, and information about anonymity, confidentiality and ethical issues. The survey was approved by the Ethics Committee of the Rectorate of Sakarya University (Approval No: 61923333/050.99-11498) on March 2, 2020.

In addition to the consent form, the survey included four parts. The first part consisted of demographic questions such as age, gender, education level, and location during the pandemic. The second part aimed to reveal health-related behaviors during the three periods of the pandemic defined for the purposes of analysis, i.e., stay home, new normal, and restrictions. This part consisted of 5-point Likert items from "never" to "always" about the protective pandemic-related behaviors such as wearing a mask, maintaining personal hygiene, and social distancing, as suggested by the Scientific Board in Turkey and the WHO. Five behaviors were questioned for each of the three defined periods separately. The value of Cronbach's alpha was calculated for 15 items of the survey and found .82, which indicates good reliability (Field, 2018). For each behavior, participants were asked to indicate how frequently they repeated the specific behavior during each period, i.e., stay home, new normal, and restrictions. Table 1 presents the examples of items in this part of the survey.

The third category consisted of open-ended questions. Here, participants were asked to justify their behaviors and write down their additional explanations related to their behaviors during each of the three defined pandemic periods. The fourth part of the survey mainly aimed to reveal the sources of information about COVID-19 that participants followed during the pandemic and the trust in scientists on the decision of vaccination. First, participants were asked how often they followed a particular source of information, e.g., scientists, healthcare providers, MoH, WHO, politicians, religious leaders, about the pandemic by giving the choices. Then, participants were asked whether the probability of getting a COVID-19 vaccine (free of charge) would change based on the scientists' advice. Three options- "increase", "decrease", or "no change"-were provided regarding the influence of scientists' advice on the probability of individuals getting a vaccine.

Researchers established the survey questions in light of the literature review related to COVID-19 and trust in scientists. Then, four experienced researchers at a university reviewed the questions. Two of the researchers had publications in the area of measurement and evaluation; the other two had science education backgrounds (one chemistry, one science) with publications about controversial issues in Turkish society. All experts evaluated the survey based on the following criteria: clarity, objectivity, ease of reading, and content (Fraenkel et al., 2012). Based on expert suggestions, a new option, i.e., healthcare providers, was added regarding the sources of information. Moreover, an amendment regarding the trust question was made for the clarity of the item. After these amendments, the survey link was shared in social media to be completed by limited participants as a pilot study. For the pilot study, six participants completed the survey, and

Table 1 Example items from the survey

\begin{tabular}{llllll}
\hline Use of Mask & Never & Rarely & Sometimes & Often & Always \\
\hline Stay Home Period (March-May) & $\square$ & $\square$ & $\square$ & $\square$ & $\square$ \\
New Normal Period (June-September) & $\square$ & $\square$ & $\square$ & $\square$ & $\square$ \\
Restrictions Period (October-January) & $\square$ & $\square$ & $\square$ & $\square$ & $\square$ \\
\hline
\end{tabular}


the researchers gathered feedback on clarities of the items and technical issues, especially about ease of reading. Following the pilot study, the final version of the survey was administered.

\subsection{Data Collection and Analysis}

The Survey About Behaviors in the COVID-19 Pandemic was applied through social media. The link to the survey was accessible for about 3 weeks from February 11 to February 23, 2021. Respondents who approved the consent form were allowed to continue answering the survey questions.

Regarding the analysis of open-ended questions, all answers were first gathered and organized into a single file. Then, two of the researchers evaluated the answers using the codebook. The coders were provided only the participants' numbers and their open-ended responses to ensure objectivity in coding, during the coding process. No other information was shared.

First, the answers were categorized into two: Description of behavior and justification for behavior. For the purpose of the study, two researchers analyzed the justifications for behaviors using the codebook, which was prepared for coders by all researchers. The coding process included simultaneous coding that referred to the use of two or more codes for a single datum when there was more than one meaning assigned to the content (Miles et al., 2014). Researchers selected the most common and possible reasons as the main categories, e.g., science, citizenship, economics, belief, policy, and psychology-related reasons. In advance of analysis, two coders agreed on the meanings of the codes and their implications in verbal data to sustain reliability. Indicators were identified to define the subcodes to give the full particulars of each category. For instance, the category for the citizenshiprelated reasons included responsibility (acting as a responsible citizen to prevent spreading the infection) and following various resources. Science-related indicators included scientific explanations, referring to scientists and/or scientific-based institutions as an information source, research/data-based thinking, and questioning the reliability, consistency, and the truth of explanations.

After the first version of the codebook was constituted, the first cycle of coding was carried out through the whole qualitative data. Subsequently, the research team met to discuss additional indicators that emerged during the first cycle of coding. For instance, the pandemic terms were added as a new category. The second cycle of coding, based on the revised version of the codebook, was performed by the same two researchers throughout the whole data set. Another meeting was held to discuss the new codes that emerged in the second coding cycle. For instance, the policy-related category required having two opposing codes to describe the trust in government authorities. Therefore, for instance, trust and distrust in the Ministry of Health were defined as separate subcodes. After the second coding process was completed for all the data, interrater reliability was calculated, which resulted in an $83.8 \%$ agreement between the coders, which is within the suggested range (Miles \& Huberman, 1994).

After ensuring the shared meaning of the codes for the coders, researchers performed the third cycle of the coding process for the whole data set again. After the third coding cycle, both coders agreed that the codes were adequate to represent all kinds of responses. The final version of the codebook is presented in Table 2.

After the researchers reached a consensus for all codes, the participants were grouped into two groups: "trust group" included the participants who trusted in scientists; "non-trust 


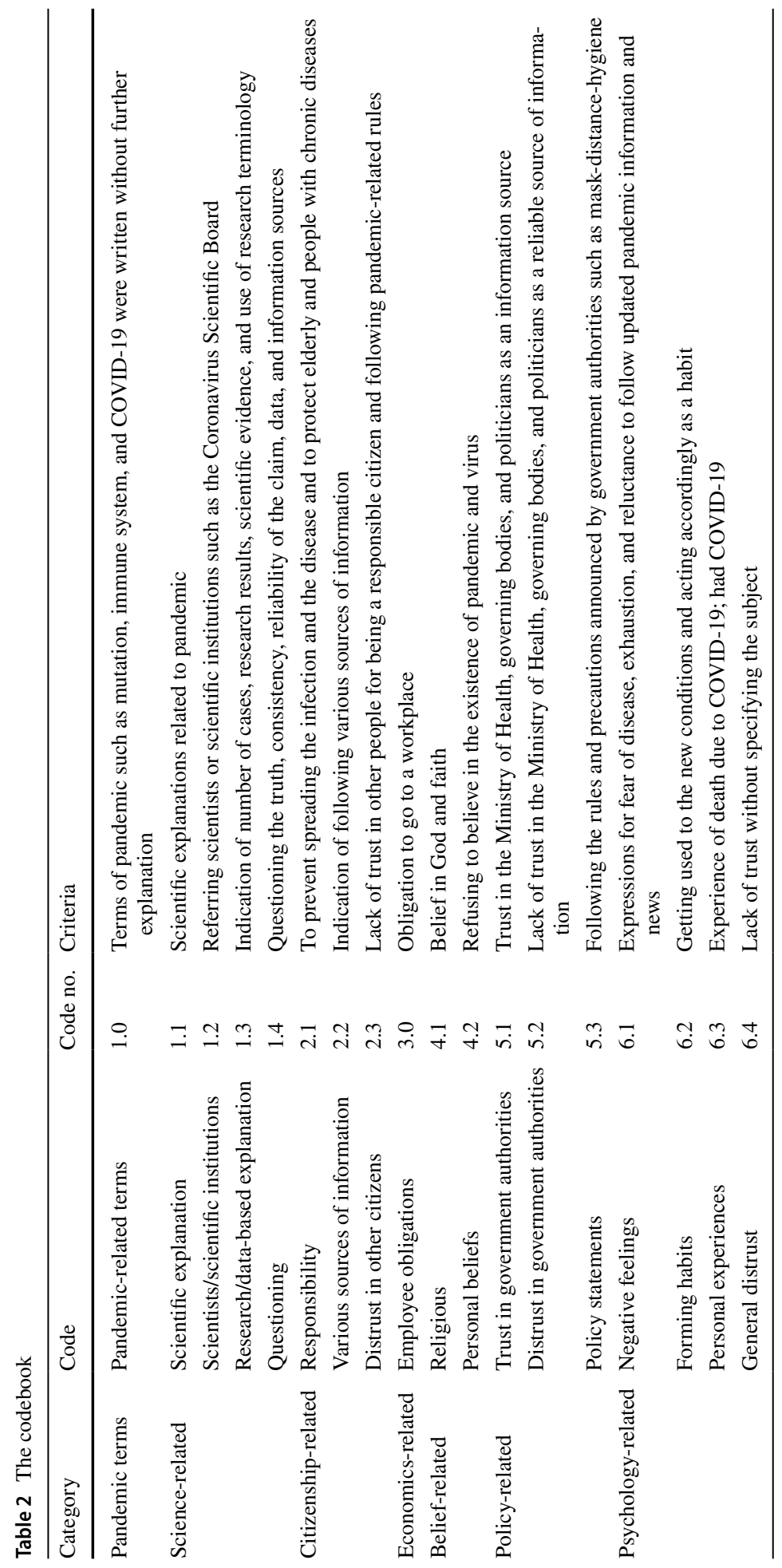


group" included the participants who did not trust in scientists in the context of vaccine. In other words, the trust group involved participants who stated that the probability of getting a vaccine would increase if it was suggested by scientists, whereas the non-trust group involved participants who indicated that the probability of getting a vaccine would decrease or would not change even though scientists suggested it.

\section{Results}

RQ 1. How did participants who trusted in scientists and those who did not trust in scientists about getting the COVID-19 vaccine report their source of information and health-related behaviors during the three defined periods of the pandemic between March 2020 and January 2021?

This study found that $74.6 \%$ of the participants belonged to the trust group, whereas $25.4 \%$ of them belonged to the non-trust group. It was also found that there was a difference between the trust group and non-trust group in terms of their sources of information about COVID-19. As can be seen in Fig. 4, the trust group followed the scientists as the

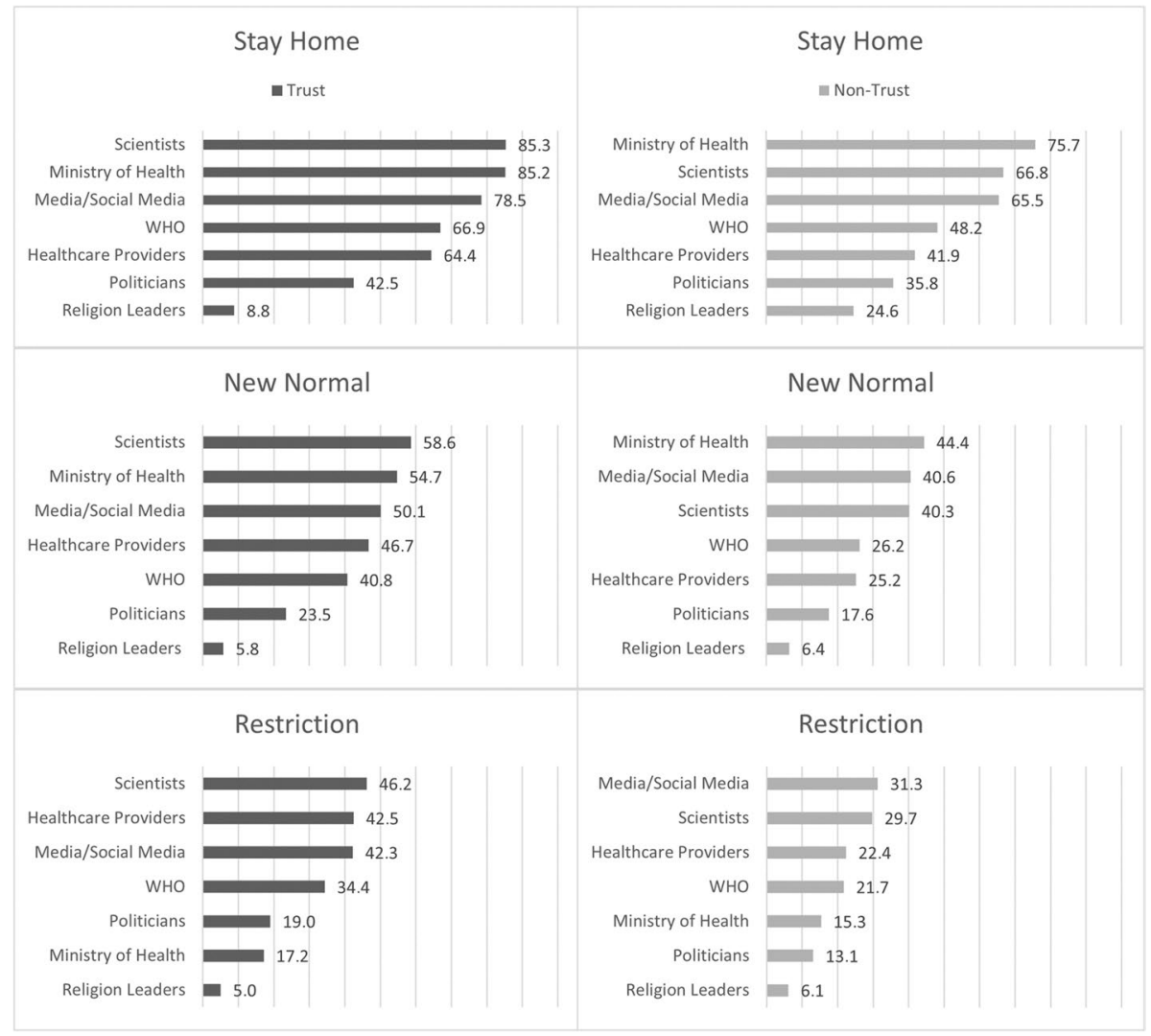

Fig. 4 Percentage distribution of sources of information 
main information source in all three periods of the pandemic. On the other hand, for the non-trust group, the $\mathrm{MoH}$ in Turkey was the main information source for the first and second periods of the pandemic. In the third period, there was a sharp decrease in the number of participants who followed the $\mathrm{MoH}$ as a source of information. As a result, in the pandemic's third period, the MoH in Turkey became the fourth source of information for the non-trust group and fifth for the trust group.

In order to mitigate the risks of the pandemic, the main motto, including the three key suggestions of the Ministry of Health disseminated through social media, websites, TV, and newspapers, was "Wear Mask, Keep Personal Hygiene, and Keep Social Distancing." Therefore, wearing masks, washing hands, using cologne or disinfectant, home visits, and going to markets were determined as pandemic-related behaviors. The second item of the motto, i.e., washing hands and using cologne or a disinfectant, is maintaining personal hygiene. Behaviors, including home visits and going to markets, highlighted social distancing. These behaviors were investigated through 5-point Likert items for three periods of the pandemic. Table 3 represents the distribution of participants' answers.

In the pandemic's first period, wearing a mask was not included in the advice in the MoH guidelines in Turkey (2020). Even before wearing a mask in public areas was ordered mandatory as part of the official COVID-19 mitigation policy, more than $84 \%$ of the participants in each of the non-trust and trust groups stated that they wore masks. In the second period of the pandemic, starting from June 22, 2020, with advice of the MoH in Turkey, the Turkish Ministry of Interior ordered the use of masks in public mandatory (Karadağ, 2020). In this period, there was an increase in the use of masks in both trust and non-trust groups. In the third period, it was observed that participants who wore masks always or often reached over $90.9 \%$ in the non-trust group and $95.4 \%$ in the trust group. In all periods of the pandemic, it was observed that the trust group always had a higher percentage of using masks than the non-trust group. The graphs show the percentages of participants who responded often and always for the given items (Fig. 5).

The second key recommendation as part of the COVID-19 prevention policy was maintaining personal hygiene. In all three analyzed periods of the pandemic, washing hands seems to be a common practice for the trust and non-trust groups. Regarding hygiene, in the first period, the total rate of participants who declared to use cologne or disinfectant as always and often in the non-trust group was $75.7 \%$; it was $85.0 \%$ for the trust group. In the pandemic's third period, this rate was decreased for the non-trust $(66.4 \%)$ and trust groups (79.5\%). Yet, washing hands and using cologne or disinfectant in all three periods of the pandemic were more common behaviors in the trust group than in the non-trust group.

The third advice to prevent COVID-19 was keeping social distancing. Regarding this policy, two behaviors were questioned: the frequency of home visits to friends/family and going to markets. Fig. 6 shows that a low percentage of participants stated that they always or often did home visits during the pandemic. Especially in the first period, it was $2.2 \%$ for the non-trust group and $1.1 \%$ for the trust group. On the other hand, going to markets was a more frequent behavior for both groups. Although the percentage of participants who stated that they always and often went shopping increased in the second and third periods, the percentages in the trust group were always less than in the non-trust group.

RQ-2. How did participants who trusted in scientists and those who did not trust in scientists about getting the COVID-19 vaccine justify their health-related behaviors?

Regarding the question about justifications for behaviors, among 1233 participants, 53 of them did not write any explanations, and 614 of them only described their behavior 


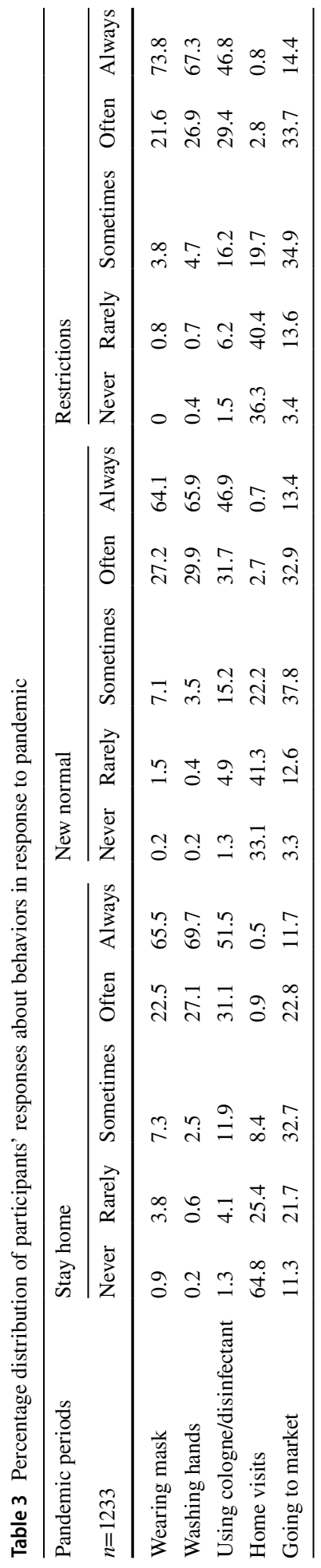




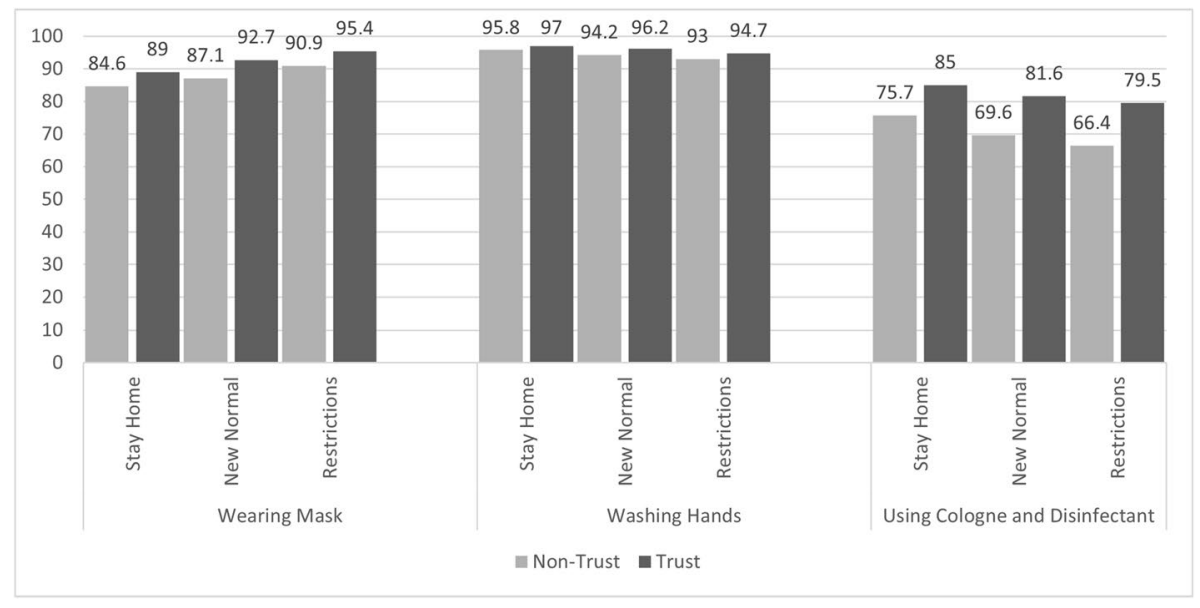

Fig. 5 Percentage of wearing mask, washing hands, and using cologne and disinfectant

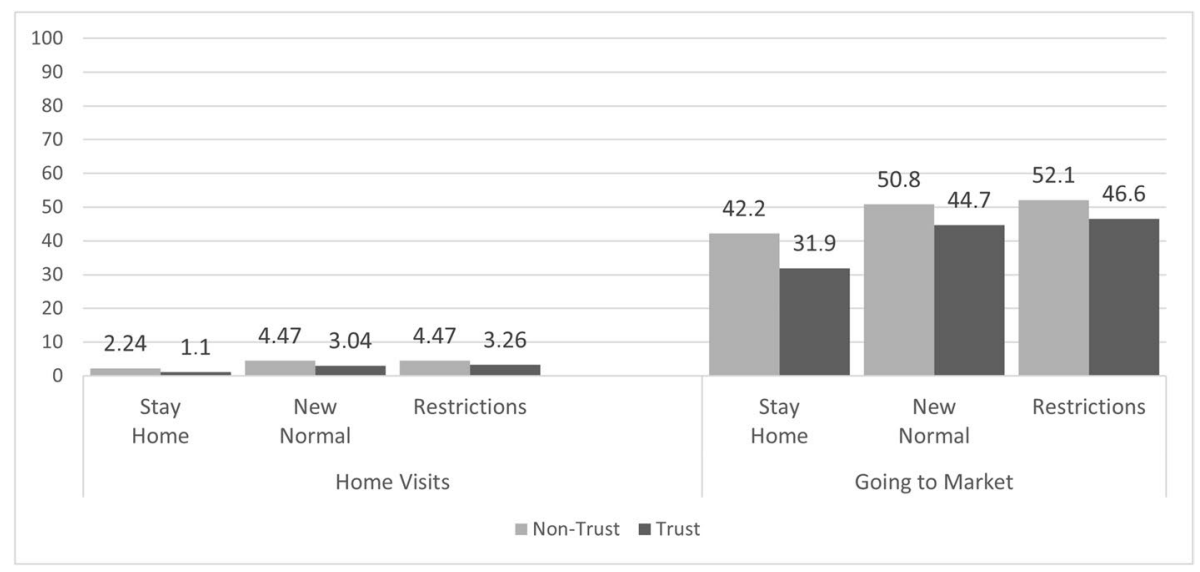

Fig. 6 Percentage of home visits and going to market

during the pandemic or the way their behavior changed without giving any reasons. There were 746 justifications coded in total for 566 participants. In the trust group, 459 participants provided justifications; their responses were analyzed with 581 codes. The non-trust group included 107 participants with 135 codes for analysis.

The total number of codes $(n=746)$ was analyzed with respect to seven categories of the final version of the codebook. The results showed that almost half of the codes $(49.0 \%)$ were science-related reasons. Policy-related reasons $(15.1 \%)$ were the second major code, followed by psychology-related reasons $(14.5 \%)$ and citizenship-related reasons $(12.8 \%)$. Although they were minor, pandemic terms (6.8\%), belief-related reasons (1.3\%), and economic-related reasons $(0.4 \%)$ were also stated to justify behavior.

The codes were examined comparing the groups for each category in order to understand whether there was a difference in justification of a particular behavior. It was observed that both groups explained the reasons for their behaviors by referring to scientific knowledge 
or skills or scientists/scientific institutions mainly. Moreover, policy-related explanations, citizenship-related explanations, and psychology-related explanations were over $10 \%$ in both groups (Fig. 7). These categories and their subcategories were presented with examples of quotations in the following sections.

Science-Related Category The science-related category was the major source of justification for the behavior of both groups. The percentage was higher in the trust group (50.9\%) than in the non-trust group (40.7\%). Science-related codes included four subcategories, i.e., scientific explanation, scientists/scientific institutions, research/data-based explanations, and questioning of the reliability of the research or data. Scientific explanation referred to the responses that suggested a scientific explanation for pandemic terms that caused justification for the behavior. At this point, it was not expected for those scientific explanations to be completely correct since scientific explanations also changed during the pandemic. Among the science-related codes, this subcode was ranked lowest for the trust group $(9.1 \%)$. The non-trust group $(14.5 \%)$ relied on this reasoning more than the trust group (Fig. 8).

The second subcode for the science-related reason referred to scientists/scientific institutions. This included responses that mention either following the recommendations of scientists and healthcare providers such as doctors or credible scientific institutions such as the WHO and the Coronavirus Scientific Board. Related phrases were used to indicate them as a source of information to gain scientific knowledge and to justify their behaviors. The data revealed that following a scientist/scientific institution was a more common justification for the trust group (22.6\%) than the non-trust group (12.7\%).

The code for research/data-based explanation was used in responses that indicated the number of cases, emphasized research results on pandemic, and the use of research terminology while explaining the reasoning behind their behaviors. It also embraced the

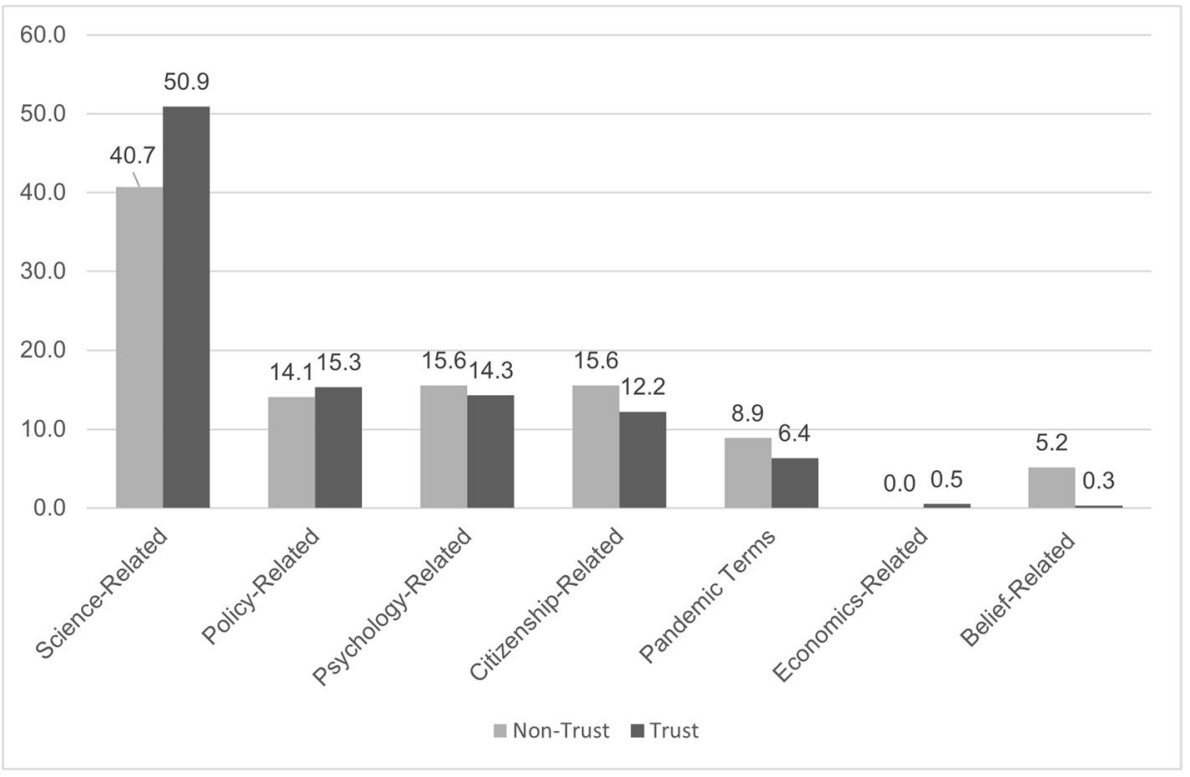

Fig. 7 Percentage distribution of categories within the trust and the non-trust groups 


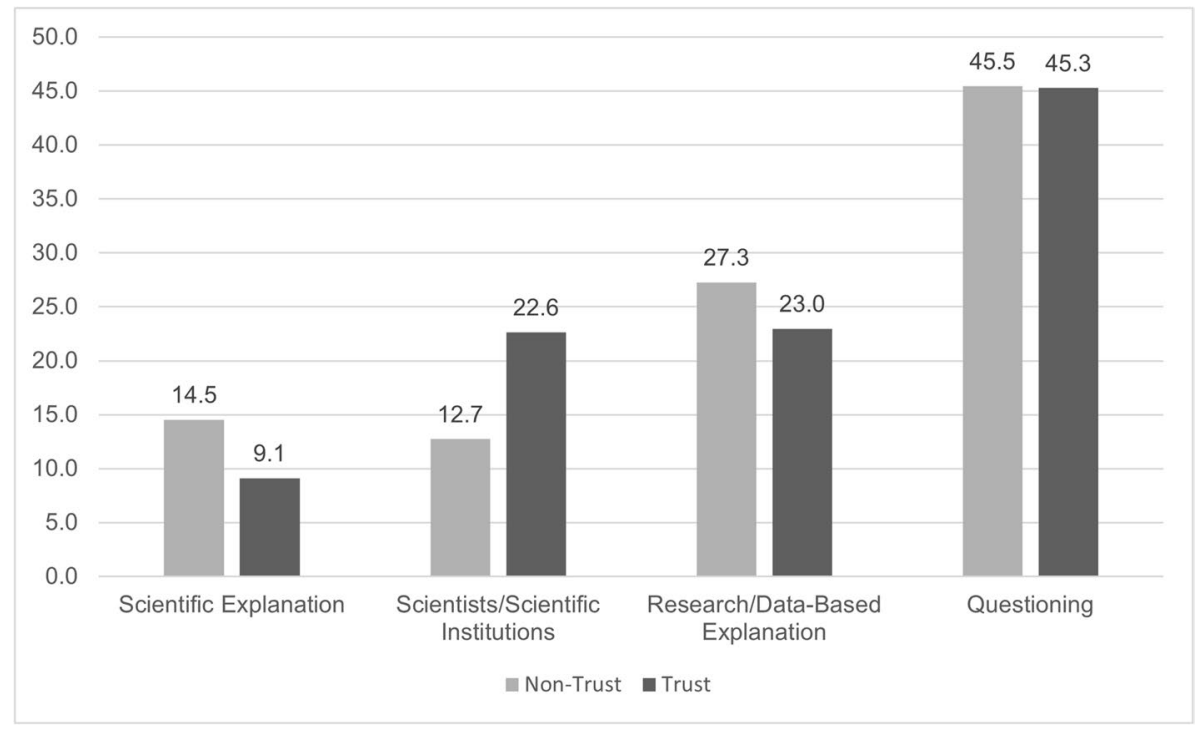

Fig. 8 Percentage distribution of science-related codes among the trust and the non-trust groups

responses that indicated the increase in knowledge level (or gaining new scientific knowledge) and learning more about the pandemic based on evidence. Although this was the second-highest ranked subcode for the trust group (23.0\%), it was used less frequently than the non-trust group (27.3\%).

Within this context, questioning was described as searching for and questioning the truth, consistency, and reliability of knowledge or data. In addition, trustworthiness of the information sources to gain scientific information was also questioned by several participants and thus coded likewise. It can be seen that questioning was highest ranked in both trust and non-trust groups. They also had close rates of questioning codes, i.e., $45.3 \%$ and $45.5 \%$, respectively. Examples of participants' responses are presented in Table 4.

Policy-Related Category Policy-related category included three subcodes: trust in government authorities, distrust in government authorities, policy statements. The codes referred to justifications based on the instructions and statements of government authorities, especially the Ministry of Health.

Trust in government authorities referred to those who explicitly stated that they had full confidence in the Ministry of Health or governing bodies on pandemic-related decisions and statements. The responses, which stated the Ministry of Health as the only trustworthy information source, were also placed in this subcode. Trust in government authorities ranked lowest in both groups: $21.3 \%$ in the trust group; $10.5 \%$ in the non-trust group (Fig. 9).

Distrust in government authorities referred to the lack of trust in the Ministry of Health and the information provided by government authorities. This caused a change in behaviors and preferences for following a source of information. The responses mainly pointed to the problem regarding the inconsistent data and information about COVID-19 positive case numbers publicly shared by the Ministry of Health. This was expressed as one of the major reasons behind the lack of trust in the Ministry of Health. Lack of trust in government 
Table 4 Examples of science-related responses of both groups

\begin{tabular}{|c|c|}
\hline Code & Response $^{\mathrm{a}}$ \\
\hline Scientific explanation & $\begin{array}{l}\text { "As a precaution against the virus, I started to use products with higher } \\
\text { alcohol content." (ID:156, trust) } \\
\text { "I learned that antibacterial materials did not kill the virus." (ID:719, } \\
\text { Non-trust) }\end{array}$ \\
\hline Scientists/scientific institution & $\begin{array}{l}\text { "I have always followed scientists." (ID: } 29, \text { Trust) } \\
\text { "I have been following scientists and the WHO since the beginning of } \\
\text { the pandemic." (ID:1158, Non-trust) }\end{array}$ \\
\hline Research/data-based explanation & $\begin{array}{l}\text { "As the number of patients, intensive care patients, and death has } \\
\text { increased, a change occurred in my behaviors. I paid more attention to } \\
\text { the hygiene of my surroundings." (ID: 628, Trust) } \\
\text { "Changing knowledge (findings indicating the virus cannot live on sur- } \\
\text { faces such as clothes and shopping bags)." (ID:1211, Non-trust) }\end{array}$ \\
\hline Questioning & $\begin{array}{l}\text { "I followed less resources since misinformation has increased." (ID: } \\
922, \text { Trust) } \\
\text { "The fact that I understand the importance of resource selection. I think } \\
\text { misinformation increased." (ID:575, Non-trust) }\end{array}$ \\
\hline
\end{tabular}

${ }^{\mathrm{a}}$ The responses of the participants were originally written in Turkish. Example responses were translated by the research team.

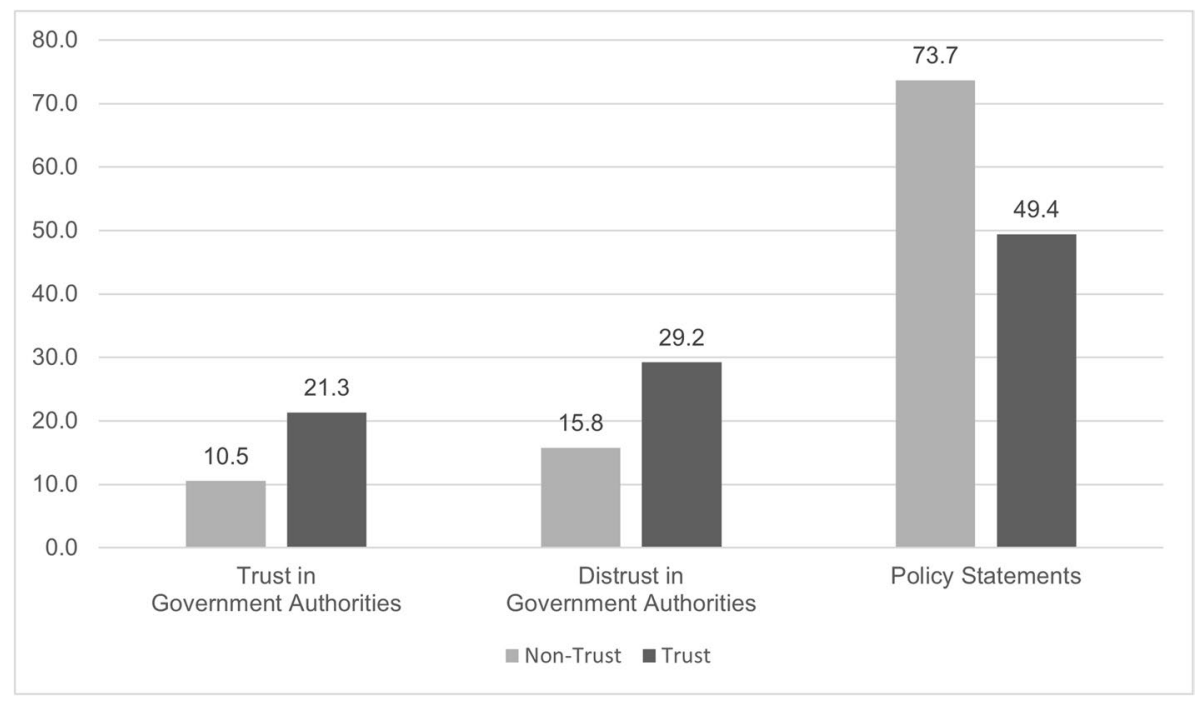

Fig. 9 Percentage distribution of policy-related subcodes among trust and non-trust groups

authorities was much higher in the trust group (29.2\%) compared with the non-trust group $(15.8 \%)$.

The final subcode, policy statements, follows the rules and precautions announced by government authorities mainly by the Ministry of Health. Examination of policy-related codes revealed that the percentage of participants following policy statements was higher in the non-trust group (73.7\%) than the trust group (49.9\%). Additionally, it was the major 
policy-related reason for behaviors in both groups. Examples of participants' responses are presented in Table 5.

Citizenship-Related Category Citizenship-related codes included responsibility, various sources of information, and distrust in other citizens. Responsibility referred to those who intended to prevent the spread of the disease. The rate of responsibility within the citizenship-related category was $46.5 \%$ for the trust group and $42.9 \%$ for the non-trust group. Participants mainly expressed that they avoided being a source of infection and took specific measures to protect the elderly and those with chronic diseases. Some participants expressed that they changed their behavior based on the information gained from multiple perspectives.

The second subcode, various sources of information, indicated the use of multiple sources and searching for more information about the pandemic, as can be expected from responsible citizens. Both the trust and non-trust groups used various sources of information, $49.3 \%$ and $57.1 \%$, respectively. Finally, distrust in other citizens represented a lack of trust arising from people who did not observe the key suggestions for protection and, therefore, risk the lives of others. Its rate was $4.2 \%$, while none of the non-trust group expressed this reason. Examples of participants' responses are presented in Table 6.

Psychology-Related Category Participants expressed several psychological reasons to justify their behaviors. These reasons produced four subcodes. "Negative feelings" was the code for those who expressed fear of infection as well as the exhaustion due to the asocial lifestyle the pandemic brought to our daily lives. Within the psychology-related category, this was the most frequent reason expressed in both trust $(60.2 \%)$ and non-trust groups $(80.0 \%)$. For instance, participants wrote: "Frankly, I was terrified and I acted very carefully" (ID: 58, Group: Trust, Code no: 6.1) and "Fear of getting sick" (ID: 1226, Group: Non-trust, Code no: 6.1). "Forming habits" was used for those who indicated that they got used to new life conditions and made adjustments in their behaviors accordingly. This was

Table 5 Examples of policy-related responses of both groups

\begin{tabular}{ll}
\hline Code & Response $^{\text {a }}$ \\
\hline Trust in government authorities & "The explanations of the Ministry of Health give confidence." \\
& (ID:1197, Trust) \\
& Ifound the explanations of the Ministry of Health more trustworthy." \\
& (ID:729, Non-trust) \\
"I have decided not to follow the Ministry of Health since I have lost & faith in the truthfulness of data shared by the Ministry. My trust in \\
the government has decreased." (ID:349, Trust) & "In terms of a source of information r egarding the COVID-19, my \\
trust in the Ministry of health has been shaken. I have searched \\
hygiene issues myself and have become more informed. I have no \\
trust left for the Ministry of Health and healthcare organizations." \\
(ID:529, Non-trust) \\
"I applied the rules of washing hands and social distancing just like \\
the Minister of Health said." (ID:1176, Trust) \\
"The Minister of Health still emphasizes that we should be careful \\
about mask-distance-hygiene." (ID:589, Non-trust) \\
Policy statements
\end{tabular}

${ }^{\text {a }}$ The responses of the participants were originally written in Turkish. Example responses were translated by the research team. 
Table 6 Examples of citizenship-related responses of both groups

\begin{tabular}{ll}
\hline Code & Response $^{\text {a }}$ \\
\hline Responsibility & "To prevent the infection of the disease. The idea of being infected without \\
& showing any symptoms. To protect people who have to be in my sur- \\
& rounding from the virus." (ID:622, Trust) \\
"Chronical disease of my sibling. Wish of not carrying the disease from \\
the intense work environment to home." (ID:52, Non-trust) \\
"I think following various resources is more beneficial as I wanted to \\
Various sources of information myself what is right and what is wrong based on consulting to \\
various resources and following different perspectives." (ID:67, Trust) \\
"I get into more comprehensive search. I did not gain information only \\
from one source." (ID:689, Non-trust) \\
"Since I think that those who are around me disregard the hygiene rules, I \\
enhanced my own hygiene habits." (ID:215, Trust)
\end{tabular}

${ }^{\mathrm{a}}$ The responses of the participants were originally written in Turkish. Example responses were translated by the research team.

expressed more often in the trust group $(15.7 \%)$ than in the non-trust group $(4.8 \%)$. Personal experiences, another subcode, referred to those who experienced COVID-19 disease personally, experienced a death in the immediate surroundings, or consequences of personal actions that resulted in a change of behavior (i.e., getting allergies due to extensive use of disinfectants). Finally, some responses expressed a lack of trust without specifying a reason. These were coded as "general distrust." Personal experiences and general distrust had the lowest rates for the two groups.

\section{Discussion}

In this study, the main focus was to explore participants' trust in scientists about getting the vaccination, the sources of information they followed about the pandemic, participants' health-related behaviors, and the reasons behind their behaviors. A main result of the study was the high percentage of the participants who trusted in scientists about getting a vaccine. This result was consistent with the results of Hamilton et al.'s (2015) study. Participants' education level in the current study was mostly at the undergraduate or graduate level. According to Myers et al. (2017), participants' high education level has a positive effect on trust in scientific research. Distrust in scientists about vaccination was also observed among the study participants (25.4\%). Similarly, Henley and McIntyre (2020) highlighted distrust of $20 \%$ or more of respondents among 19 different countries. They argued that "the truth about the harmful effects of vaccines is being deliberately hidden from the public." The lack of trust in science may slow the progress in the field to fight against the pandemic (Huber et al., 2019).

Another crucial result of the study was in regard to the sources of information that participants used to follow COVID-19. Both trust and non-trust groups followed scientists, the $\mathrm{MoH}, \mathrm{WHO}$, and media/social media as their main sources of information about COVID19 , especially in the pandemic's first two defined subperiods. This result was also in line with the literature in terms of sources of information followed by the individuals during COVID-19 (McFadden et al., 2020). For the trust group, during the three terms defined, scientists have been the most frequent sources of information followed. On the other hand, 
for the non-trust group until September 2020, the MOH was the most followed source of information. However, during the last period (September 2020-January 2021), the MoH had a sharp decrease in both groups, which may be related to the MoH's announcement about a change in methodology in calculating the number of COVID-19 positive cases. The study participants also expressed their feelings of distrust in $\mathrm{MoH}$, as a reason of not following MOH's announcements and explanations about the pandemic (the distrust in government authorities code in Table 5). Mardin (2021) also emphasized that the public questioned the reliability of the information provided by the MoH. The present study confirmed that consistency among the explanations and trust in a source were important justifications while choosing sources of COVID-19 information.

In addition to scientists, the $\mathrm{MoH}$, and the WHO, media/social media was also among the highly followed sources of information for both groups. Indeed, during the last term, media became the mostly followed source of information for the non-trust group. During the COVID-19 pandemic, doctors and scientists started to give speeches in media more frequently. For instance, in New York City, one of the earliest and most severely hit cities by the pandemic, medical doctors and scientists explained the reasons why it was important to frequently follow the public policy suggestions via TV as part of the government policy, just like in many major cities across the world. The aim was to enlighten citizens to follow the guidelines by building trust in scientists. On the other hand, as evident in the literature, sources such as blogs, newspapers, and social media also involved misinformation and disinformation about COVID-19 and vaccines (Allington et al., 2021a; Jennings et al., 2021). This means that the participants of the study followed media with a varying degree of reliability. Under the science-related category, it was observed that a group of participants from both trust and non-trust groups questioned the reliability of the data and explanations; they also highlighted the spread of misinformation in the context of COVID-19. Misinformation and disinformation on the pandemic and vaccination may influence people's opinion (Dror et al., 2020) and hence their behaviors. This is one reason why citizens need to be scientifically informed. Hence, such citizens are critical; they are able to question the reliability of the sources and claims in order to fit in degree of confidence in the context of sciencerelated issues.

Another focus of the study was the participants' behavior in response to the COVID19 pandemic. In many countries, people changed their health-related behaviors and habits during the pandemic to overcome COVID-19 (Pagliaro et al., 2021; Romer \& Jamieson, 2020). Similarly, participants of the study reported that they mostly complied with scientists' suggestions during COVID-19. Under the policy-related category, it was observed that $73.7 \%$ of the non-trust group and $49.4 \%$ of the trust group referred to the motto, namely, masks-distance-hygiene, to justify their behaviors. The motto was developed with collaboration of scientists, health organizations, and governments and announced by $\mathrm{MoH}$ as the main policy of Turkey to fight COVID-19. In a way, the high number of references to the motto indicated the power of collaboration among government authorities, scientists, and international organizations. It was also observed that there were slight changes in terms of the frequency of acting in line with the suggested behaviors among the three periods of the pandemic in Turkey. These changes might be related to other policies, conditions of Turkey, and new research findings. For instance, at the beginning of COVID-19, it was difficult to find a mask, and the WHO and MoH suggested masks for healthcare staff rather than citizens (WHO, 2020c; MoH, 2020). Then, this problem was solved, and wearing masks has become compulsory in the country as of June 2020 (Karadağ, 2020). Moreover, in all periods, it was observed that the trust group always had a higher tendency in acting in line with the suggestions of the Scientific Board than the non-trust group. Plohl and Musil 
(2020) also highlighted that trust in scientists is a key factor in acting in line with the suggestions of the scientific community.

For the justification of their behaviors, participants expressed mainly science-, policy-, psychology-, and citizenship-related explanations. The trust group referred to sciencerelated explanations more than the non-trust group whereas the non-trust group referred to belief-related explanations more than the trust group to justify their behaviors. The percentages of justifications in other categories such as policy- and psychology-related explanations were close for the trust and non-trust groups. In a recent study, which explored informal reasoning and persuasion of preservice biology teachers regarding COVID-19 behaviors, similar categories emerged such as science-, policy-, and psychology-oriented reasoning (Han-Tosunoglu \& Ozer, 2021).

Pagliaro et al. (2021) discussed the role of trust toward different agents such as governments, citizens, and science as a key issue to "provide a more informative picture of individuals' reactions to COVID-19" (p. 9). In the present study, trust issues appeared in science-, policy-, and citizenship-related explanations. For instance, in science-related explanations, both trust and non-trust groups mentioned the spread of misinformation about COVID-19; they also questioned the reliability of the source, data, or research to regulate their behaviors. In policy-related explanations, both trust and non-trust groups also expressed trust or distrust of authorities as an explanation for their behaviors. In the citizenship category, participants either acted as a responsible citizen and followed the suggested behaviors to prevent the dissemination of the virus to other citizens, or they distrusted other citizens in the society and isolated themselves to be safe.

The present study was limited to participants from Turkey who use social media. Yet, the large number of participants and diversity in age, education level, and locations makes the study meaningful in terms of understanding the health-related behaviors and trust in scientists in the context of COVID-19. However, since stratified sampling was not utilized, the participants do not represent the society in Turkey. Moreover, not all the participants explained justifications for their behaviors. Further studies with participants who are representative in terms of education level, age, gender and locations need to be conducted to have a better view of the role of trust in scientists in peoples' justifications for their behaviors.

\section{Conclusion}

Trust in scientists and collaboration among scientists, government authorities, and international organizations need to be strengthened for the availability of consistent information and strategies to overcome global science-related problems. Furthermore, being a scientifically informed citizen is vital to differentiate misinformation and disinformation from reliable information. Scientifically informed citizens are expected to "assess the reliability of claims relevant to personal and social decision-making" (Allchin, 2014, p. 1). Otherwise, the effectiveness of a powerful scientific solution such as a vaccine (Haynes, 2021) may be jeopardized via lack of trust in scientists, lack of understanding of the nature of science and the way science works, and mass spread of misinformation or disinformation. In terms of the implementation of a vaccine as a public policy, it is the responsibility of government authorities and scientists to communicate the key importance of vaccination to the public effectively (Organisation for Economic Co-operation and Development [OECD], 2021). 
Science communication is a powerful tool to strengthen public trust in scientists. Scientists are primary agents in communicating and transferring scientific knowledge to the public. Public talks from scientists are also significant in the struggle with post-truth era issues. Moreover, governmental agencies contribute to science communication by referring to scientific research or statements of scientists to explain their policies. Transparency in the implementation of policies and conveying accurate information would enhance more effective communication of scientists with the public as well. Policymakers are responsible for furthering public trust in scientists for the well-being of society. Moreover, trust in scientists is necessary to establish and sustain an open and healthy dialogue among the key actors, including politicians, government authorities, and the public to overcome global problems such as the devastating COVID-19 pandemic, which can only be solved in the light of science. Briefly, a healthy, consistent, and transparent science communication needs to be practiced in building public trust and that will serve to mitigate the risks of misinformation and disinformation, both of which jeopardize the success of the fight against the COVID-19 pandemic. However, substantial public resistance against vaccination continues despite all communication efforts regarding the evidence about the safety and effectiveness of the vaccines during the COVID-19 pandemic. This implies that the factor underlying the distrust problem is a structural one that needs to be overcome with more long-term policies.

One of the long-term policies is about how to further science education in building public trust in science and scientists. Science educators and governmental agencies should work collaboratively on developing educational policies and strategies to raise scientifically informed citizens who are equipped with the necessary skills and knowledge to understand science. First of all, in order to raise scientifically informed citizens, science education should integrate a holistic understanding of the nature of science which addresses its cognitive, epistemic, and social-institutional aspects (Erduran \& Dagher, 2014). Citizens need to understand the reliable production of scientific knowledge and its ways of dissemination so that they can evaluate the developments and limits of science. These are the necessary conditions to build epistemic trust of public in science and to distinguish scientific explanations from others. Moreover, a well-established science education across the world will ensure that citizens appreciate science (Mugaloglu, 2014). In other words, they need to recognize the value of science and why a scientific claim is more reliable than any other source of information in the context of science-related issues. Thus, science education will foster public trust in science and scientists by emphasizing the explanatory power of science in context.

Data Availability Not applicable.

Code Availability Not applicable.

Author Contribution All authors contributed to the design and implementation of the research, to the analysis of the results, and to the writing of the manuscript.

\section{Declaration}

Ethics Approval Ethical Committee of Sakarya University approved the study.

Consent to Participate Informed consent was obtained from all individual participants included in the study.

Consent for Publication The authors give their consent for the publication of the manuscript titled "Exploring the role of trust in scientists to explain health-related behaviors in response to the COVID-19 pandemic" to be published in the Science \& Education journal. 
Conflict of Interest The authors declare that they have no conflict of interest.

\section{References}

Agley, J. (2020). Assessing changes in US public trust in science amid the COVID-19 pandemic. Public Health, 183, 122-125.

Allchin, D. (2014). From science studies to scientific literacy: A view from the classroom. Science and Education, 23, 1911-1932. https://doi.org/10.1007/s11191-013-9672-8

Allington, D., McAndrew, S., Moxham-Hall, V. L., \& Duffy, B. (2021a). Media usage predicts intention to be vaccinated against SARS-CoV-2 in the US and the UK. Vaccine, 39(18), 2595-2603.

Allington, D., McAndrew, S., Moxham-Hall, V., \& Duffy, B. (2021b). Coronavirus conspiracy suspicions, general vaccine attitudes, trust and coronavirus information source as predictors of vaccine hesitancy among UK residents during the COVID-19 pandemic. Psychological Medicine, 1-12.

Ateş, H. (2020). Merging theory of planned behavior and value identity personal norm model to explain pro-environmental behaviors. Sustainable Production and Consumption, 24, 169-180.

Ayalon, L. (2021). Trust and compliance with COVID-19 preventive behaviors during the pandemic. International Journal of Environmental Research and Public Health, 18(5), 2643. https://doi.org/10.3390/ ijerph18052643

Baier, A. (1986). Trust and antitrust. Ethics, 96(2), 231-260.

Barzilai, S., \& Chinn, C. A. (2020). A review of educational responses to the "post-truth" condition: Four lenses on "post-truth" problems. Educational Psychologist, 55(3), 107-119.

Battiston, P., Kashyap, R., \& Rotondi, V. (2020). Trust in science and experts during the COVID-19 outbreak in Italy. SSM - Population Health, 13, 100721. https://doi.org/10.1016/j.ssmph.2020.100721

Bhattacharya, R., Devinney, T. M., \& Pillutla, M. M. (1998). A formal model of trust based on outcomes. Academy of Management Review, 23(3), 459-472.

Bicchieri, C., Fatas, E., Aldama, A., Casas, A., Deshpande, I., Lauro, M., et al. (2021). In science we (should) trust: Expectations and compliance across nine countries during the COVID-19 pandemic. PloS one, 16(6), e0252892.

Bostan, S., Erdem, R., Öztürk, Y. E., Kılıç, T., \& Yılmaz, A. (2020). The effect of COVID-19 pandemic on the Turkish society Electronic Journal of General Medicine, 17(6):em237.https://doi.org/10.29333/ ejgm/7944

Goodman, J., \& Carmichael, F. (2020). Coronavirus: Bill Gates 'microchip' conspiracy theory and other vaccine claims fact-checked. BBC Reality Check. May.

Castelfranchi, C., \& Falcone, R. (1998, July). Principles of trust for MAS: Cognitive anatomy, social importance, and quantification. In Proceedings International Conference on Multi Agent Systems (Cat. No. 98EX160) (pp. 72-79). IEEE.

Castell, S., Charlton, A., Clemence, M., Pettigrew, N., Pope, S., Quigley, A., Shah, J. N., \& Silman, T. (2015). Public attitudes to science. Ipsos Mori Report for Department for Business Innovation and Skills, $1,202$.

Carmichael, F., \& Goodman, J. (2020, December 2). Vaccine rumours debunked: Microchips, 'altered DNA' and more. BBC news, https://www.bbc.com/news/54893437

Clements, J. M. (2020). Knowledge and behaviors toward COVID-19 among US residents during the early days of the pandemic: Cross-sectional online questionnaire. JMIR Public Health and Surveillance, 6(2), e19161.

Coleman, A. (2020, August 12). Hundreds dead' because of COVID-19 misinformation. BBC news, https:// www.bbc.com/news/world-53755067

Creswell, J. W. (2014). Qualitative, quantitative and mixed methods approaches. Sage.

Creswell, W. J., \& Clark, V. L. P. (2018). Designing and conducting mixed methods research ( $3^{\text {rd }}$ ed.). SAGE Publications.

Dror, A. A., Eisenbach, N., Taiber, S., Morozov, N. G., Mizrachi, M., Zigron, A., Srouji, S., \& Sela, E. (2020). Vaccine hesitancy: The next challenge in the fight against COVID-19. European Journal of Epidemiology, 35(8), 775-779.

Erduran, S. (2020). Reframing science education in light of the COVID-19 pandemic. School Science Review, 102(378), 38-43.

Erduran S., \& Dagher Z. R. (2014). Reconceptualizing the nature of science for science education: scientific knowledge, practices and other family categories. Dordrecht: Springer.

Field, A. (2018). Discovering statistics using IBM SPSS Statistics $\left(5^{\text {th }}\right.$ ed.). SAGE. 
Ford, M. (2008). 'Grasp of practice' as a reasoning resource for inquiry and nature of science understanding. Science \& Education, 17(2), 147-177.

Fraenkel, J. R., Wallen, N. E., \& Hyun, H. H. (2012). How to design and evaluate research in education ( $^{\text {th }}$ ed.). New York: McGraw-Hill.

Funk, C., Rainie, L., \& Page, D. (2015). Public and scientists' views on science and society. Pew Research Center, 29 .

Greene, C. M., \& Murphy, G. (2021). Quantifying the effects of fake news on behavior: Evidence from a study of COVID-19 misinformation. Journal of Experimental Psychology: Applied. Advance online publication. https://doi.org/10.1037/xap0000371

Gölemerz, T., Akdaş, M., Paslı, S., Farhana, S., \& Jankowska, K. (2020). COVID-19'a ilişkin bilgi, tutum ve uygulama $(K A P)$ de ğerlendirme çalışması. The Turkish Red Crescent.

Hamilton, L. C., Hartter, J., \& Saito, K. (2015). Trust in scientists on climate change and vaccines. Sage Open, 5(3), 1-13. https://doi.org/10.1177/2158244015602752

Han-Tosunoglu, C., \& Ozer, F. (2021). Exploring pre-service biology teachers' informal reasoning and decision-making about COVID-19. Science \& Education, 1-31.

Hardin, R. (2002). Trust and trustworthiness. Russell Sage Foundation.

Haynes, B. F. (2021). A new vaccine to battle Covid-19. The New England Journal of Medicine, 384(5), 470-471. https://doi.org/10.1056/NEJMe2035557

Henley, J., \& McIntyre, N. (26 Oct 2020). Survey uncovers widespread belief in 'dangerous' Covid conspiracy theories. The Guardian. Available at https://www.theguardian.com/world/2020/oct/26/surveyuncovers-widespread-belief-dangerous-covid-conspiracy-theories

Huber, B., Barnidge, M., Gil de Zúniga, H., \& Liu, J. (2019). Fostering public trust in science: The role of social media. Public understanding of science, 28(7), 759-777.

Irzik, G., \& Kurtulmus, F. (2021). Well-ordered science and public trust in science. Synthese, 198(19), $4731-4748$.

Jennings, W., Stoker, G., Willis, H., Valgardsson, V., Gaskell, J., Devine, D., ... \& Mills, M. C. (2021). Lack of trust and social media echo chambers predict COVID-19 vaccine hesitancy. medRxiv, 2021-01.

Karadağ, A. (2020, September 08). Turkey mandates mask-wearing in all public areas. Anadolu Agency. https://www.aa.com.tr/en/health/turkey-mandates-mask-wearing-in-all-public-areas/1966671

Keelan, J., Pavri-Garcia, V., Balakrishnan, R., \& Wilson, K. (2010). An analysis of the Human Papilloma Virus vaccine debate on Myspace blogs. Vaccine, 28(6), 1535-1540.

Keelan, J., Pavri-Garcia, V., Tomlinson, G., \& Wilson, K. (2007). YouTube as a source of information on immunization: A content analysis. Journal of the American Medical Association, 298(21), 2482-2484.

Lee, S., Kim, T., Lee, E., Lee, C., Kim, H., Rhee, H., et al. (2020). Clinical course and molecular viral shedding among asymptomatic and symptomatic patients with SARS-CoV-2 infection in a community treatment center in the Republic of Korea. JAMA Internal Medicine, 180(11), 1447-1452.

Lep, Ž., Babnik, K., \& Hacin Beyazoglu, K. (2020). Emotional responses and self-protective behavior within days of the COVID-19 outbreak: The promoting role of information credibility. Frontiers in Psychology, 11, 1846.

Lurie, N., Saville, M., Hatchett, R., \& Halton, J. (2020). Developing Covid-19 vaccines at pandemic speed. New England Journal of Medicine, 382(21), 1969-1973.

Mardin, F. D. (2021). Turkey's healthcare policies and the COVID-19 pandemic In: Analyses pluridisciplinaires sur la crise sanitaire COVID-19 en Turquie [online]. Istanbul: Institut français d'études anatoliennes, 1-16, https://doi.org/10.4000/books.ifeagd.3774

McFadden, S. M., Malik, A. A., Aguolu, O. G., Willebrand, K. S., \& Omer, S. B. (2020). Perceptions of the adult US population regarding the novel coronavirus outbreak. PLOS ONE, 15(4), e0231808. https:// doi.org/10.1371/journal.pone.0231808

McIntyre, L. (2018). Post-truth. MIT Press.

Meese, J., Frith, J., \& Wilken, R. (2020). COVID-19, 5G conspiracies and infrastructural futures. Media International Australia, 177(1), 30-46.

Miles, B. M., \& Huberman, A. M. (1994). Qualitative data analysis (2nd ed.). Sage Publications.

Miles, B. M., Huberman, A. M., Saldaña, J. (2014). Qualitative data analysis: A methods sourcebook and the coding manual for qualitative researchers ( $3^{\text {rd }}$ ed.). Thousand Oaks, CA: Sage.

Ministry of Health, (2020). Koronavirüs hastalı̆̆ için kişisel koruyucu ekipmanların doğru kullanımı 2019 (COVID-19) geçici rehber. Retrieved April 20, 2021, from https://khgmstokyonetimidb.saglik.gov.tr/ Eklenti/36950/0/koronavirus-hastaligi-icin-kisisel-koruyucu-ekipmanlarin-dogru-kullanimi-2019covid-19pdf.pdf

Ministry of Health (2021). COVID-19 information page. General coronavirus table. Retrieved April 24, 2021, from https://covid19.saglik.gov.tr/EN-69532/general-coronavirus-table.html. 
Mugaloglu, E. Z. (2014). The problem of pseudoscience in science education and implications of constructivist pedagogy. Science \& Education, 23(4), 829-842.

Myers, T. A., Kotcher, J., Stenhouse, N., Anderson, A. A., Maibach, E., Beall, L., \& Leiserowitz, A. (2017). Predictors of trust in the general science and climate science research of US federal agencies. Public Understanding of Science, 26(7), 843-860.

Nadelson, L. S., \& Hardy, K. K. (2015). Trust in science and scientists and the acceptance of evolution. Evolution: Education and Outreach, 8(1), 1-9.

Nadelson, L., Jorcyk, C., \& Yang, D. (2014). I just don't trust them: The development and validation of an assessment instrument to measure trust in science and scientists. School Science and Mathematics, 114(2), 76-86.

Organisation for Economic Co-operation and Development (2021). Enhancing public trust in COVID19 vaccination: The role of governments. Retrieved September 1, 2021, from https://www.oecd. org/coronavirus/policy-responses/enhancing-public-trust-in-covid-19-vaccination-the-role-of-gover nments-eae0ec5a/

Oksay, R. (2021). Yalan haberi cazip kılan ne? Neden hemen inanıoruz? Herkese Bilim Teknoloji, 283, $12-15$.

Özceylan, G., Toprak, D., \& Esen, E. S. (2020). (2020). Vaccine rejection and hesitation in Turkey. Hum Vaccin Immunother., 16(5), 1034-1039.

Pagliaro, S., Sacchi, S., Pacilli, M. G., Brambilla, M., Lionetti, F., Bettache, K., et al. (2021). Trust predicts COVID-19 prescribed and discretionary behavioral intentions in 23 countries. PloS ONE, 16(3), e0248334. https://doi.org/10.1371/journal.pone.0248334

Pitel, L. (2020). Turkey admits publishing incomplete coronavirus tally. Financial Times. Retrieved April 25, 2021, from https://www.ft.com/content/5307a438-f083-4f7f-a1da-5b0a0eaa6047

Plohl, N., \& Musil, B. (2020). Modeling compliance with COVID-19 prevention guidelines: The critical role of trust in science. Psychology, Health \& Medicine, 26(1), 1-12.

Prado, C. G. (2018). America's post-truth phenomenon: When feelings and opinions trump facts and evidence. Praeger.

Presidency of the Republic of Turkey, (2020). Ülkemizin maruz kaldı $\breve{g}$ virüs tehhidinin en klsa sürede bertaraf edilmesi için devlet olarak tüm imkanlarımızı seferbek ettik, https://www.tccb.gov.tr/ haberler/410/117037/-ulkemizin-maruz-kaldigi-virus-tehdidinin-en-kisa-surede-bertaraf-edilmesiicin-devlet-olarak-tum-imk-nlarimizi-seferber-ettik-

Romer, D., \& Jamieson, K. H. (2020). Conspiracy theories as barriers to controlling the spread of COVID-19 in the US. Social Science \& Medicine, 263, 113356.

Rousseau, D. M., Sitkin, S. B., Burt, R. S., \& Camerer, C. (1998). Not so different after all: A crossdiscipline view of trust. Academy of Management Review, 23(3), 393-404.

Shinan-Altman, S., \& Levkovich, I. (2020). COVID-19 precautionary behavior: The Israeli case in the initial stage of the outbreak. BMC Public Health, 20(1), 1-7.

Sleeth-Keppler, D., Perkowitz, R., \& Speiser, M. (2017). It's a matter of trust: American judgments of the credibility of informal communicators on solutions to climate change. Environmental Communication, 11(1), 17-40.

Spencer, J. P., Pawlowski, R. H. T., \& Thomas, S. (2017). Vaccine adverse events: Separating myth from reality. American Family Physician, 95(12), 786-794.

Timonen, J. (2020, June 25). Why is science education important? JYUnity blog. Retrieved from: https:// jyunity.fi/en/thinkers/why-is-science-education-important/

Turkish Academy of Sciences. (2020). Covid-19 pandemi değerlendirme raporu.http://www.tuba.gov. tr/files/images/2020/kovidraporu/T\%C3\%9CBA\%20Covid-19\%20Raporu\%201.\%20G\%C3\%BCnce lleme.pdf

Turkish Statistical Institute. (2021, February 4). Adrese Dayalı Nüfus Kayıt Sistemi Sonuçlarl, 2020. https://data.tuik.gov.tr/Bulten/Index? $\mathrm{p}=37210$

UNICEF (2021). 5G technology does not cause or spread coronavirus. Retrieved August 29, 2021, from https://www.unicef.org/montenegro/en/stories/5g-technology-does-not-cause-or-spread-coron avirus

van Mulukom, V., Pummerer, L., Alper, S., Bai, H., Cavojova, V., Farias, J. E. M., et al. (2020). Antecedents and consequences of COVID-19 conspiracy beliefs: A systematic review. PsyArXiv [Preprint]. https://doi.org/10.31234/osf.io/u8yah

Wardle, C., \& Derakhshan, H. (2017). Information disorder: Toward an interdisciplinary framework for research and policy making. Council of Europe report, 27, 1-107.

World Health Organization, (2020a, March 12). WHO announces COVID-19 outbreak a pandemic. https://www.euro.who.int/en/health-topics/health-emergencies/coronavirus-covid-19/news/ news/2020/3/who-announces-covid-19-outbreak-a-pandemic 
World Health Organization, (2020b, April 27). WHO Timeline - COVID-19. WHO. https://www.who.int/ news/item/27-04-2020-who-timeline\%2D\%2D-covid-19

World Health Organization, (2020c, February 27). Rational use of personal protective equipment for coronavirus disease 2019 (COVID19). https://apps.who.int/iris/bitstream/handle/10665/331215/WHO2019-nCov-IPCPPE_use-2020.1-eng.pdf

World Health Organization, (2021). Publication repository. Retrieved September 10, 2021, from https:// apps.who.int/iris/

Zhong, B. L., Luo, W., Li, H. M., Zhang, Q. Q., Liu, X. G., Li, W. T., \& Li, Y. (2020). Knowledge, attitudes, and practices towards COVID-19 among Chinese residents during the rapid rise period of the COVID-19 outbreak: A quick online cross-sectional survey. International Journal of Biological Sciences, 16(10), 17-45.

Publisher's Note Springer Nature remains neutral with regard to jurisdictional claims in published maps and institutional affiliations. 